\title{
Pulmonary function in chronic renal failure: effects of dialysis and transplantation
}

\author{
Andrew Bush, Roger Gabriel
}

\begin{abstract}
Many possible pulmonary complications of renal disease have been described, but little is known of their physiological importance or the effects on them of different forms of renal replacement therapy. Four groups were recruited, each containing 20 patients. The groups consisted of patients with chronic renal failure before dialysis (group 1); patients receiving continuous ambulatory peritoneal dialysis, never having received a transplant (group 2); patients receiving haemodialysis, never having received a transplant (group 3); and patients after their first successful cadaveric renal transplant (group 4). All were attending the same regional dialysis and transplant unit. None was known to have clinically important lung or chest wall disease. Flow-volume loops were recorded before and after $400 \mu \mathrm{g}$ of salbutamol, and plethysmographic lung volumes and airway conductance and single breath carbon monoxide transfer factor were measured. Only nine of 80 patients had normal lung function. The reductions in spirometric values were

of kidney disease are likely to become increasingly important. Chronic renal failure may affect virtually every system in the body, including the lungs. ${ }^{1}$ Pulmonary oedema and pleural effusions, attributed to fluid overload and an increase in pulmonary capillary permeability, ${ }^{2-5}$ are relatively common. Rarer complications include pulmonary fibrosis ${ }^{6}$ and calcification, ${ }^{78}$ pulmonary hypertension, haemosiderosis, ${ }^{6}$ pleuritis, ${ }^{910}$ and pleural fibrosis. ${ }^{11}$ Renal replacement therapy may also result in complications. Haemodialysis causes recurrent episodes of hypoxaemia due to partial blockage of the pulmonary capillary bed by white cells ${ }^{1213}$ or silicone microemboli. ${ }^{14}$ Renal transplantation introduces the further hazards of lung infections and lung complications from immunosuppressive drugs. Because little is known of the functional importance of these complications, we recruited 80 patients from a single renal unit to determine lung function in uraemia. There were four groups of patients: those with chronic renal failure before dialysis, those treated by continuous ambulatory peritoneal dialysis alone, those treated by haemodialysis only, and those who had undergone a first successful cadaveric renal transplant.
\end{abstract} minor. Whole lung carbon monoxide transfer factor was reduced in all groups (mean \% predicted with $95 \%$ confidence intervals: group $181 \cdot 7 \%$ (74-89\%); group $269 \cdot 7 \%(62-77 \%)$; group $387.5 \%(80-$ $96 \%)$; group $482.5 \%(78-87 \%))$. The values were significantly lower in those having continuous ambulatory peritoneal dialysis (group 2). Residual volume was reduced significantly in the group who had undergone renal transplantation $(85 \cdot 7 \%, 77-94 \%)$. There was no correlation between these changes and smoking habit, age, duration or severity of renal failure, duration of treatment, or biochemical derangement. It is concluded that abnormal lung function is common in renal disease. The main change is a reduction in carbon monoxide transfer that persists after transplantation. The likeliest explanation is that subclinical pulmonary oedema progresses to fibrosis before transplantation. The fibrosis may worsen further to cause the reduced residual volume in the recipients of grafts.

As the life expectation of patients with chronic

\section{Methods}

PATIENTS

We studied eighty patients who were clinically and radiologically free from recent acute or known chronic lung and chest wall disease. Patients were excluded if the cause of their renal disease was likely to affect the lung, such as systemic lupus erythematosus, or if they had received drugs that can damage the lungs, such as cyclophosphamide. None had any clinical evidence of fluid retention. Routine chest radiography was not performed.

Twenty patients (group .1) were in chronic renal failure that did not require dialysis. All had a serum creatinine concentration above 250 $\mu \mathrm{mol} / \mathrm{l}$ (twice the upper limit of normal). Twenty patients (group 2) were receiving continuous ambulatory peritoneal dialysis; none of this group had ever been treated with regular haemodialysis, or had undergone transplantation. As a previous study ${ }^{15}$ had shown that the presence or absence of dialysis fluid in the abdomen did not affect lung function, we studied these patients with the abdomen containing dialysate. Twenty patients (group 3) were being treated with regular haemodialysis, never having had regular peritoneal dialysis or undergone transplantation. They were studied renal failure increases systemic complications
Department of Renal Medicine, St Mary's Rospital,

Correspondence to: Dr Bush

Accepted 29 March 1991 
Table 1 Details of patients studied (20 in each group): mean (SD) values unless otherwise specified

\begin{tabular}{|c|c|c|c|c|}
\hline & Group 1 & Group 2 & Group 3 & Group 4 \\
\hline $\begin{array}{l}\text { Age }(\mathrm{y}) \\
\text { Sex }(\mathrm{M} / \mathrm{F}) \\
\text { Duration }(\mathrm{y})^{\star} \\
\text { Haemoglobin }(\mathrm{g} / \mathrm{dl}) \\
\text { Albumin }(\mathrm{g} / \mathrm{dl}) \\
\text { Calcium (mmol/l) } \\
\text { ALP (units) } \\
\text { Smokers } \dagger\end{array}$ & $\begin{aligned} 51 \cdot 0 & (13 \cdot 4) \\
15 / 5 & \\
1 \cdot 5 & (1 \cdot 1) \\
10 \cdot 2 & (2 \cdot 2) \\
40 & (5) \\
2 \cdot 21 & (0 \cdot 25) \\
121 & (47) \\
5 / 11 / 4 & \end{aligned}$ & $\begin{array}{cl}59 \cdot 7 & (8.9) \\
14 / 6 & \\
0.9 & (0.5) \\
9 \cdot 0 & (1 \cdot 9) \\
34 & (4) \\
2.20 & (0.22) \\
104 & (37) \\
9 / 3 / 8 & \end{array}$ & $\begin{aligned} 44.9 & (3 \cdot 0) \\
18 / 2 & \\
2 \cdot 1 & (0 \cdot 5) \\
7 \cdot 4 & (1 \cdot 8) \\
41 & (4) \\
2 \cdot 38 & (0 \cdot 24) \\
103 & (51) \\
9 / 6 / 5 & \end{aligned}$ & $\begin{array}{cl}38 \cdot 9 & (2 \cdot 3) \\
13 / 7 & \\
5 \cdot 3 & (1 \cdot 2) \\
12 \cdot 8 & (2 \cdot 6) \\
43 & (3) \\
2 \cdot 40 & (0 \cdot 17) \\
78 & (34) \\
6 / 6 / 8 & \end{array}$ \\
\hline \multicolumn{5}{|l|}{ Diagnoses } \\
\hline $\begin{array}{l}\text { Glomerulonephritis } \\
\text { Adult polycystic kidneys } \\
\text { Diabetes mellitus } \\
\text { Chronic pyelonephritis } \\
\text { Other } \\
\text { Unknown }\end{array}$ & $\begin{array}{l}4 \\
4 \\
1 \\
4 \\
7\end{array}$ & $\begin{array}{r}2 \\
3 \\
3 \\
-1 \\
11\end{array}$ & $\begin{array}{r}8 \\
-1 \\
- \\
3 \\
8\end{array}$ & $\begin{array}{l}8 \\
- \\
3 \\
2 \\
7\end{array}$ \\
\hline
\end{tabular}

*Known duration of renal failure or its treatment.

†Numbers of never smokers/ex-smokers/current smokers.

ALP-alkaline phosphatase.

within 24 hours of a routine biweekly dialysis. In all patients in groups 2 and 3 good control of biochemical measures and fluid balance had been attained for at least three months before the study. Twenty patients (group 4) were studied at least three months after their first successful cadaver renal transplantation. At the time of the study all patients with transplants were receiving prednisolone $15 \mathrm{mg}$ and azathioprine $150 \mathrm{mg}$ daily. Clinical details of the 80 patients are given in table 1 . Patients with renal failure of unknown cause include those who presented with bilaterally shrunken kidneys and no evidence of systemic disease and who did not undergo renal biopsy.

\section{STUDY DESIGN}

On the day of the study a history was taken and physical examination performed. A routine blood sample was taken for a full blood count and biochemical profile. No attempt was made to measure creatinine clearance because of the problems with outpatient 24 hour urine collections. We assumed that glomerular filtration rate was closely correlated with the reciprocal of serum creatinine concentration. ${ }^{16} \mathrm{We}$ recorded flow-volume loops before and after inhalation of $400 \mu \mathrm{g}$ of salbutamol from a pressurised aerosol, using an Ohio 840 dry rolling seal spirometer. Forced expiratory volume in one second $\left(\mathrm{FEV}_{1}\right)$, forced vital capacity (FVC), and peak expiratory and inspiratory flow (PEF, PIF) were recorded. Total lung capacity (TLC), residual volume (RV), and specific airway conductance (sGaw) were measured with a Fenyves and Gut whole body plethysmograph. A 10 second single breath test measured carbon monoxide transfer factor (TLCO), accessible lung volume (VA), and carbon monoxide transfer/litre of accessible lung (Kco-that is, TLCo/VA), a PK Morgan Model $\mathrm{C}$ transfer test apparatus being used. At least three reproducible tests were carried out for each measurement and the best was recorded. Comparisons were made with the normal ranges from Cotes, ${ }^{17}$ except for PIF (predicted $=75 \%$ predicted $\mathrm{PEF}^{18}$ ). TLCo and Kco were corrected for haemoglobin concentration. ${ }^{19}$ We calculated the mean and $95 \%$ confidence intervals (CI) for each measurement in each group.

\section{ANALYSIS}

Measurements for each group and for smokers, ex-smokers, and non-smokers were compared by analysis of variance; linear regression was used to assess correlations between measurements. As the ages and builds of the patients differed considerably all the lung function analyses were performed on the results expressed as percentages of predicted normal, except for sGaw; here normal values (greater than $1.3 \mathrm{~s}^{-1} \mathrm{kPa}^{-1}$ ) do not vary with age and the range is wide, so the use of a percentage value is less valuable than an absolute measurement.

Complete data for each individual were also inspected and allocated to a particular overall pattern (table 3)-obstructive if the $\mathrm{FEV}_{1} / \mathrm{FVC}$ ratio was reduced with either TLC or RV increased and the other lung volume not reduced; pure restrictive if the $\mathrm{FEV}_{1} / \mathrm{FVC}$ ratio was increased with either TLC or RV reduced and the other lung volume not increased; and mixed if both obstructive and restrictive features were present.

\section{Results}

There were differences in age, haemoglobin, calcium, albumin, and alkaline phosphatase between the four groups, as expected ( $p<0.01$; table 1). Haemoglobin, albumin, and calcium concentrations were highest and alkaline phosphatase activity lowest in the renal transplant group, confirming that biochemical control was improved after cadaveric renal transplantation. Serum albumin concentration was lowest in the group having continuous ambulatory peritoneal dialysis $(F=16 \cdot 3$, $\mathrm{p}<0.001$ ).

The mean $(95 \% \quad \mathrm{CI})$ lung function measurements for each group are shown in table 2 and numbers with an abnormal measurement in table 3. Mean sGaw was within the normal range in all groups.

In group 1 (patients with renal failure not requiring dialysis) spirometric values were essentially within the normal range. There was 
Table 2 Results of lung function tests (means with 95\% confidence intervals), expressed as percentages of predicted normal (except for specific airways conductance, $s$ Gaw) in each group of 20

\begin{tabular}{lcccc}
\hline & Group 1 & Group 2 & Group 3 & Group 4 \\
\hline FEV & $92 \cdot 7$ & $87 \cdot 6$ & $90 \cdot 0$ & $95 \cdot 1$ \\
& $(82-104)$ & $(78-97)$ & $(83-98)$ & $(88-102)$ \\
FVC & $95 \cdot 9$ & $87 \cdot 6$ & $90 \cdot 2$ & $96 \cdot 9$ \\
& $(87-105)$ & $(80-95)$ & $(81-99)$ & $(89-105)$ \\
PEF & $83 \cdot 1$ & $85 \cdot 6$ & $84 \cdot 3$ & $89 \cdot 5$ \\
& $(70-96)$ & $(76-96)$ & $(75-94)$ & $(81-99)$ \\
PIF & $86 \cdot 7$ & $80 \cdot 0$ & $78 \cdot 7$ & $93 \cdot 6$ ‡ \\
& $(76-97)$ & $(71-89)$ & $(67-91)$ & $(85-102)$ \\
TLC & $103 \cdot 1$ & $93 \cdot 4$ & $97 \cdot 7$ & $92 \cdot 7$ \\
& $(97-109)$ & $(86-101)$ & $(91-104)$ & $(87-99)$ \\
RV & $116 \cdot 2$ & $106 \cdot 6$ & $112 \cdot 4$ & $85 \cdot 1$ \\
& $(102-131)$ & $(90-123)$ & $(102-123)$ & $(77-94)$ \\
VA & $94 \cdot 2$ & $83 \cdot 0$ & $89 \cdot 7$ & $88 \cdot 5$ \\
& $(88-100)$ & $(78-88)$ & $(83-96)$ & $(83-94)$ \\
TLCO & $81 \cdot 7$ & $69 \cdot 7$ & $87 \cdot 5$ & $82 \cdot 5$ \\
& $(74-89)$ & $(62-77)$ & $(80-96)$ & $(78-87)$ \\
Kco & $92 \cdot 6$ & $91 \cdot 8$ & $105 \cdot 5$ & $99 \cdot 3$ \\
& $(84-101)$ & $(81-103)$ & $(95-116)$ & $(93-105)$ \\
sGaw $\dagger$ & $1 \cdot 39$ & $1 \cdot 50$ & $1 \cdot 69$ & $1 \cdot 96$ \\
& $(0 \cdot 96-1 \cdot 8)$ & $(1 \cdot 0-2 \cdot 0)$ & $(1 \cdot 2-2 \cdot 1)$ & $(1 \cdot 4-2 \cdot 5)$ \\
\hline
\end{tabular}

$\star_{\mathrm{n}}=18$.

†Absolute values $\left(\mathrm{s}^{-1} \mathrm{kPa}^{-1}\right)$.

For abbreviations see under "Study design."

a minor increase in RV and a normal TLC. TLCo was substantially reduced. There was no significant correlation between TLCO \% predicted and known duration of renal failure.

In group 2 (patients receiving continuous ambulatory peritoneal dialysis) there were minor reductions in all spirometric measurements, with normal absolute lung volumes. There was a substantial reduction in TLco but no correlation between the reduction in TLCO and the duration of continuous ambulatory peritoneal dialysis. In group 3 (haemodialysis) there were minor reductions in all spirometric variables, a small increase in RV, a normal TLC, and reduced TLCO. There was no correlation between the duration of haemodialysis and the reduction in TLCo. Lung function changes could not be related to dialyser material ${ }^{1213}$ as the patients had used many different types.

In group 4 (with renal transplants) spirometric values were normal. Lung volumes $(12 / 20)$ and TLCo $(13 / 20)$ were reduced. There was no correlation between the reduction in TLCO and the time elapsed after transplantation or the time spent on dialysis. Only three patients had had peritoneal dialysis alone before transplantation; these patients did not differ obviously from the other patients in the group. When the \% predicted values for trans-

Table 3 Numbers of patients in each group of 20 with particular abnormalities of lung function (figures in parentheses are numbers of patients who have never smoked)

\begin{tabular}{|c|c|c|c|c|c|}
\hline \multirow{6}{*}{$\begin{array}{l}\text { Abnormal FEV, or FVC } \\
\text { Abnormal TLC or RV } \\
\text { Abnormal TLCo or KCo } \\
\text { Abnormal sGaw* } \\
\text { All normal }\end{array}$} & Group 1 & Group 2 & Group 3 & \multicolumn{2}{|c|}{ Group 4} \\
\hline & 7 (1) & 9 (3) & $8 \quad(4)$ & 4 & (2) \\
\hline & 7 (2) & 7 (3) & $13(7)$ & 12 & (4) \\
\hline & $14 \quad(4)$ & 17 (7) & $14(7)$ & 13 & (4) \\
\hline & 11 (2) & $10 \quad(4)$ & 9 (3) & 9 & (3) \\
\hline & $1(一)$ & 1 (1) & $4(1)$ & 3 & (1) \\
\hline Obstructive pattern $\dagger$ & 9 (3) & $6(1)$ & $4 \quad(2)$ & 1 & $(-)$ \\
\hline Restrictive pattern $\dagger$ & $4(-)$ & 6 (2) & $6(2)$ & 10 & (5) \\
\hline Mixed pattern & $1(-)$ & $3(2)$ & 4 (3) & 1 & $(-)$ \\
\hline TLCO or Kco only abnormal & 5 (2) & 4 (3) & $2(1)$ & 5 & $(-)$ \\
\hline
\end{tabular}

*Outside normal range (above $1.3 \mathrm{~s}^{-1} \mathrm{kPa}^{-1}$ )

tSee under "Analysis" for definitions.

For abbreviations see under "Study design." planted patients with normal renal function (serum creatinine $<120 \mu \mathrm{mol} / 1, \mathrm{n}=11$ ) were compared with those for patients with renal impairment $(n=9)$ the latter showed greater reductions in $\mathrm{FEV}_{1}$ (mean (SE) 101 (2.8) $v 88$ (6.2); $\mathrm{p}<0.05)$ and FVC (104 (4.3) v 89 (5.5); $\mathrm{p}<0.05)$. Other measurements were similar.

A reversible component of airway obstruction was diagnosed if either or both the $\mathrm{FEV}_{1}$ and $\mathrm{FVC}$ rose by more than $10 \%$ after salbutamol. Four patients $(5 \%)$ met these criteria, two in group 2 , one in group 1 , and one in group 3.

There wereno significant differences between groups for spirometric values, TLC, sGaw, $\mathrm{VA}$, or KCo (analysis of variance). In group 4 (with renal transplants) RV was lower than in the other three groups $(F=5.05, p<0.01)$. In group 2 (continuous ambulatory peritoneal dialysis), TLCo was lower than in the other three groups $(F=5 \cdot 10, p<0 \cdot 01)$. There was no difference between non-smokers, current smokers, and ex-smokers for any measurement, whether all 80 patients were considered or each group separately. There was also no correlation in any group between the reduction in TLCO and serum creatinine concentration or its reciprocal, duration of renal failure or its treatment, albumin or calcium concentration, or alkaline phosphatase activity apart from a weak inverse correlation between TLCO and serum albumin in the group having haemodialysis $(r=-0.57$, $\mathrm{p}<0.01$ ). There was no significant correlation between RV and any of these measurements in group 4.

\section{Discussion}

We studied 80 patients with kidney disease, all selected for the absence of overt lung disease. This is the first report to compare groups of patients undergoing different forms of treatment in the same renal unit. Our four study groups were not matched, however, and the study was cross sectional, so comparisons between groups must be cautious. Although the patients were selected at random from those attending the renal unit, there was a substantial predominance of men ( 60 of 80 studied). This may in part reflect different incidences of certain renal diseases in men. ${ }^{20}$ Our main finding was a reduction in carbon monoxide transfer factor with nearly normal spirometric values in all groups, including those with successful renal transplants. Only nine patients had completely normal lung function. We were not able to correlate lung function abnormalities with smoking habit, age, duration or severity of renal failure, or other biochemical derangement.

The most common pathological condition of the lungs in chronic renal failure is pulmonary oedema, usually due to a combination of fluid overload and abnormal permeability of the pulmonary microcirculation..$^{2-5}$ Although our patients were free from overt oedema, minor degrees of fluid retention are virtually impossible to detect clinically, and are the likeliest cause of the reduction in carbon monoxide transfer factor in our patients with renal failure 
and dialysis. Similar findings have been reported by others for patients with chronic renal failure ${ }^{21}$ or undergoing haemodialysis. ${ }^{22-24}$ We found no acute change in lung function after instilling $2 \cdot 2$ litres of dialysis fluid into the abdomen. ${ }^{15}$ Although the group having continuous ambulatory peritoneal dialysis as a whole had a lower carbon monoxide transfer factor than those having haemodialysis, the difference is unlikely to be of major clinical importance except in those with severe pre-existing pulmonary disease. It is also arguable whether haemodialysis would be tolerated by these patients as TLCo may fall further before haemodialysis owing to increased fluid overload and as there may be an acute deterioration in lung function during the dialysis period. ${ }^{12} 13$

The lack of correlation with duration of renal failure or extent of biochemical impairment is not surprising. Patients often present in established renal failure, and the time of onset is impossible to establish. Uraemic pulmonary toxicity is likely to be multifactorial, and may differ with different patterns of renal disease. ${ }^{25}$ The chemical factors that may damage the lung in uraemia have not been determined.

What is surprising, and described for the first time, is the reduction in carbon monoxide transfer in the patients with a renal transplant and the finding of a reduced residual volume in this group. An isolated reduction in residual volume in otherwise healthy people has usually indicated the presence of important lung disease. ${ }^{2627}$ We cannot determine whether these changes are due to progressive and possibly irreversible pretransplant changes, or to an additional hazard introduced by transplantation. The changes could be the result of repeated infections. ${ }^{28}$ Azathioprine is known to cause subacute alveolitis, ${ }^{29}$ but not low grade chronic changes. Comparison with other patients immunosupressed with cyclosporin would be of interest. A further hypothesis is that respiratory muscle dysfunction might be important. We did not test this in our study, but it seems an unlikely cause of a reduced residual volume. Mouth pressures and sniff transdiaphragmatic pressures were normal in patients having continuous ambulatory peritoneal dialysis in our previous study. ${ }^{15}$ Other workers have described respiratory muscle weakness in patients having continuous ambulatory peritoneal dialysis, however. ${ }^{30}$ The patients with transplants were clinically much better nourished than the other groups, which would decrease the likelihood of serious respiratory myopathy.

Comments on the possible pathological abnormalities leading to these physiological changes must necessarily be speculative. We believe that the likeliest cause of the low carbon monoxide transfer factor before transplantation is subclinical pulmonary oedema or interstitial fibrosis secondary to recurrent pulmonary oedema. Clinical methods of assessing lung and whole body water are insensitive, and the absence of overt oedema does not rule out this hypothesis. Pulmonary oedema would be favoured by increased vascular permeability, fluid overload, and a low serum albumin concentration, and this hypothesis is supported to some extent by the weak inverse correlation between TLCO and albumin in the haemodialysis group, and the fact that the lowest TLCO occurred in the group with the lowest albumin (continuous ambulatory peritoneal dialysis). Pulmonary oedema in renal failure is multifactorial, however, and is unlikely to correlate closely with any single measurement. The low carbon monoxide transfer factor after transplantation is unlikely to be due to fluid overload, as there was no difference between the transplanted patients with and without normal serum creatinine. Uraemic pulmonary oedema may have progressed to interstitial fibrosis in these patients and this would not regress even after successful transplantation. The low residual volume, not found in any other group, suggests that fibrosis may even worsen.

We conclude that abnormalities of lung function are very common in renal failure, the major finding being a reduction in carbon monoxide transfer factor. Although haemodialysis may induce acute changes in lung function, ${ }^{1213}$ there seems to be no additional effect on lung function. Continuous ambulatory peritoneal dialysis was associated with a slightly greater reduction in carbon monoxide transfer factor than was found in predialysis and haemodialysis patients. After transplantation the changes were still present, and residual volume was reduced. The pathological basis of these changes cannot be determined from this study. Survival of patients on dialysis and after transplantation is increasing, and non-renal abnormalities are therefore likely to be of increasing importance. Further studies are needed to determine the cause of lung function abnormalities in otherwise apparently healthy patients with kidney disease.

1 Bush A, Gabriel R. The lungs in uraemia: a review. $J R$ Soc Med 1985;78:849-55.

2 Gibson DG. Haemodynamic factors in the development of acute pulmonary oedema in renal failure. Lancet 1966; ii: $1217-20$.

3 Crosbie WA, Snowden S, Parsons V. Changes in lung capillary permeability in renal failure. $B M J$ 1972;iv: 388-90.

4 Rackow EC, Fern EI, Sprung C, Grodman RS. Uremic pulmonary edema. Am J Med 1978;64:1084-8.

5 Belcher NG, Rees PJ. Changes in pulmonary clearance of technetium labelled DTPA during haemodialysis. Thorax 1986;41:381-5.

6 Fairshter RD, Vaziri ND, Mirahmadi MK. Lung pathology in chronic hemodialysis patients. Int J Artif Organs 1982;5:99-102.

7 Rubini ME, Coburn JW, Maccry SG, Shinaberger JH. Renal osteodystrophy: some therapeutic considerations relative to longterm dialysis and transplantation. Arch Intern Med 1969;124:663-9.

8 Mootz JR, Sagel SS, Roberts TH. Roentgenographic manifestations of pulmonary calcifications. Radiology 1973;107:55-60.

9 Nidus BD, Matalon R, Cantacuzino D, Eisinger RP. Uremic pleuritis-a clinicopathological entity. N Engl J Med 1969;281:255-6.

10 Comty CM, Cohen SL, Shapiro FL. Pericarditis in chronic uremia and its sequels. Ann Intern Med 1971;75:173-83.

11 Reyman TA. Subacute constrictive uremic pericarditis. $A m$ J Med 1969;46:972-5.

12 Craddock PR, Fehr J, Brigham KL, Kronenberg RS, Jacob HS. Complement and leukocyte-mediated pulmonary dysfunction in hemodialysis. N Engl J Med 1977;296: 769-74.

13 Hakim RM, Breillatt EJ, Lazarus JM, Port FK. Complement activation and hypersensitivity reactions to dialysis membranes. $N$ Engl J Med 1984;311:878-82. 
14 Leong A S-Y, Disney APS, Gove DW. Spallation and migration of silicone from blood-pump tubing in patients on hemodialysis. N Engl J Med 1982;306:135-40.

15 Bush A, Miller J, Peacock AJ, Sopwith T, Gabriel R Denison D. Some observations on the role of the abdomen in breathing in patients on peritoneal dialysis. Clin $\mathrm{Sci}$ 1985;68:401-6.

16 Rutherford WE, Blandin J, Miller JP, Greenwalt AS, Vara JD. Chronic progressive renal disease: rate of change of serum creatinine concentration. Kidney Int 1977;11: 62-70.

17 Cotes JE. Lung function: assessment and application in medicine. 4th ed. Oxford: Blackwell, 1979:365-87.

18 Denison DM, Du Bois R, Sawicka E. Pictures in the mind Br J Dis Chest 1983;77:35-50.

19 Cotes JE, Dabbs JM, Elwood PC, Hall AM, McDonald A Saunders MJ. Iron-deficiency anaemia: its effects on transfer factor for the lung (diffusing capacity) and ventilatransfer factor for the lung (diffusing capacity) and ventila-
tion and cardiac frequency during submaximal exercise. Clin Sci 1972;42:325-5.

20 Rashid HU, Papiha SS, Agnoyamnis B, et al. The associations of HLA and other genetic markers with glomerulonephritis. Hum Genet 1983;63:38-44.

21 Lee HY, Stretton TB, Barnes AM. The lungs in renal failure. Thorax 1975;30:46-53.

22 Daum S, Janota M, Boudik F. Pulmonary diffusing capacity and its components in patients with uremia. Bull Physiopathol Respir 1966;2:83-94.

23 Zidulka A, Despar PJ, Milic-Emili J, Anthoiseu NR. Pulmonary function with acute loss of excess lung water by hemodialysis in patients with chronic uremia. Am J Med hemodialysis in

24 Forman J, Ayres LN, Miller C. Pulmonary diffusing capacity in chronic renal failure. $\mathrm{Br} J$ Dis Chest 1981;75:55-60.

25 Bush A. The lungs in uremia. Semin Respir Med 1988;9: 273-82.

26 Schwarz MI, Whitcomb ME, French JB. Significance of an isolated reduction of the residual volume. Am Rev Respir Dis 1971;103:430-2.

27 Owens MW, Kinasewitz GT, Anderson WM. Clinical significance of an isolated reduction in residual volume. Am Rev Respir Dis 1987;138:1377-80.

28 Doak PB, Becroft DMO, Harris EA, et al. Pneumocystis carinii pneumonia-transplant lung. QJ Med 1973;42. carinii

29 Carmichael DJS, Hamilton DV, Evans DB, Stovin PGI, Calne RY. Interstitial pneumonitis secondary to azathioprine in a renal transplant patient. Thorax 1983;38: 951-2.

30 Gomez-Fernandez P, Agudo SL, Caltrava JM, et al. Respiratory muscle weakness in patients under continuous ambulatory peritoneal dialysis. Nephron 1984;36:219-23. 